\title{
SÍNTESIS DE LOS RIESGOS CLIMÁTICOS QUE AFECTAN AL ESPACIO EUROPEO
}

\author{
Jorge Olcina Cantos
}

\section{RESUMEN}

El territorio europeo es tributario de riesgos variados de origen atmosférico. Lluvias abundantes o intensas que provocan inundaciones, oleadas de frío, advecciones saharianas, sequías y tormentas de granizo forman el catálogo de episodios meteorológicos de rango extraordinario en Europa. Algunas regiones europeas se encuentran entre las zonas de riesgo máximo de alguno de estos eventos atmosféricos a escala planetaria. Se presenta un mapa síntesis que delimita las zonas de riesgo de cada unos de los episodios atmosféricos extraordinarios que afectan a Europa, base para la realización de una catalogación de climas basada en los riesgos climáticos propios de cada ámbito planetario.

Palabras clave: riesgos climáticos. Calendario de riesgo. Areas afectadas. Mapa de riesgos.

\begin{abstract}
European territory is tributary of varied atmospheric risk. Abundant or torrential rain that causes several floods, cold and heat waves, drought, hail storms are the meteorological episodes with extraordinary values. Some european regions are one of the most importat risk areas caused on atmospheric events in the world. In this paper, we show a synthesis map of risk areas for each one of this event, basis of a new climatic classification founded on this kind of viewpoint.
\end{abstract}

Key words: climatic risk, risk calendar, affected areas, risk map.

La diversidad de tiempos y climas que presenta el territorio europeo impone variedad de riesgos climáticos. Sin olvidar el mayor impacto económico y territorial vinculado a otros riesgos naturales (volcanes y sismos) que tienen en los países de la orla mediterránea, Mar Negro y Caucaso las áreas de mayor peligrosidad en relación con el contacto de las placas tectónicas africana y euroasiática, el catálogo de riesgos climáticos que afectan a los países europeos incluye: lluvias abundantes y continuadas que causan desborda- 
miento de grandes colectores fluviales; lluvias torrenciales que provocan avenidas de ríos y ramblas; temporales de viento; temporales de frío y nieve; olas de calor; sequías y tormentas de granizo (vid. mapa $\mathrm{n}^{\circ}$ 1). Aunque el espacio europeo no es un área especialmente conflictiva en el conjunto del planeta, por pérdidas económicas y fallecimientos anuales causados por episodios meteorológicos extremos, algunos de sus países o regiones dentro de ellos presentan índices de peligrosidad de los más elevados del mundo (vid. cuadro $\mathrm{n}^{\circ} 1$ ). Hay que recordar que la Comisión Europea en coordinación con los estados miembros de la Unión tiene comprometida la redacción de un documento de carácter estratégico (Perspectiva Europea de Desarrollo Territorial), cuyo avance se presentó en junio de 1997, que debe contemplar políticas sobre la ordenación del territorio, la gestión de las aguas y la reducción de los riesgos naturales.

No obstante, sorprende que los riesgos naturales, en particular climáticos, no merezcan un tratamiento más amplio y específico en el extenso «Informe Dobříšs sobre Medio Ambiente en Europa (Agencia Europea de Medio Ambiente, 1998). A lo largo de sus más de setecientas páginas tan sólo hay referencias parciales y apenas dos páginas (p. 394 y 395) están dedicadas en exclusiva al análisis de las «catástrofes naturales» (tormentas e inundaciones, olas de calor, incendios y sequías, junto a seismos y volcanes), con un tratamiento descriptivo y puntual donde no se detalla ni calendario ni áreas de riesgo, además de olvidar riesgos climáticos de amplia repercusión en el espacio europeo (olas de frío). Ello no hace sino confirmar que el estudio de riesgos y catástrofes naturales, por definición multidisciplinar, tradicionalmente ha sido vinculado a la protección civil y no ha merecido consideración, sino parcialmente, como asunto del medio ambiente de los Estados. Las autoridades europeas deben ir modificando, progresivamente, esta consideración de los riesgos naturales que constituyen una cuestión medioambiental de primer orden donde cuentan aspectos preventivos y curativos en un enfoque global.

Cuadro 1

MUERTES POR RIESGOS CLIMÁTICOS EN EUROPA. 1990-1998

\begin{tabular}{|c|c|c|c|}
\hline Año & $\mathbf{N}^{0}$ muertos & Países más afectados & Causas \\
\hline 1990 & 126 & 126 en Reino Unido y Francia & Borrascas profundas de enero y febrero \\
\hline 1991 & 133 & 107 en Rumania & Rotura de presa en el río Tuzla \\
\hline 1992 & 74 & 63 en Francia & Lluvias torrenciales de septiembre (22-23) \\
\hline 1993 & 476 & 239 en Georgia & Avalancha \\
\hline 1994 & 397 & 208 en Rusia & Ola de frío \\
\hline 1995 & 621 & 442 en Rusia & Ola de frío \\
\hline 1996 & 324 & $\begin{array}{l}200 \text { en Europa Oriental } \\
86 \text { en España }\end{array}$ & $\begin{array}{l}\text { Ola de frío } \\
\text { Catástrofe de Biescas }\end{array}$ \\
\hline 1997 & 264 & $\begin{array}{l}100 \text { en Polonia, Chequia y Alemania } \\
62 \text { en Azores y Badajoz }\end{array}$ & $\begin{array}{l}\text { Lluvias e inundaciones } \\
\text { Lluvias torrenciales, avalanchas e inundaciones }\end{array}$ \\
\hline 1998 & 690 & $\begin{array}{l}377 \text { en Europa Oriental } \\
146 \text { en Italia }\end{array}$ & $\begin{array}{l}\text { Ola de frío } \\
\text { Lluvias y avalanchas en Campania }\end{array}$ \\
\hline
\end{tabular}

FuENTE: Anuario Natural Disasters in the World (1990-1995). I.T.G.E. Informes anuales Swiss Re. 


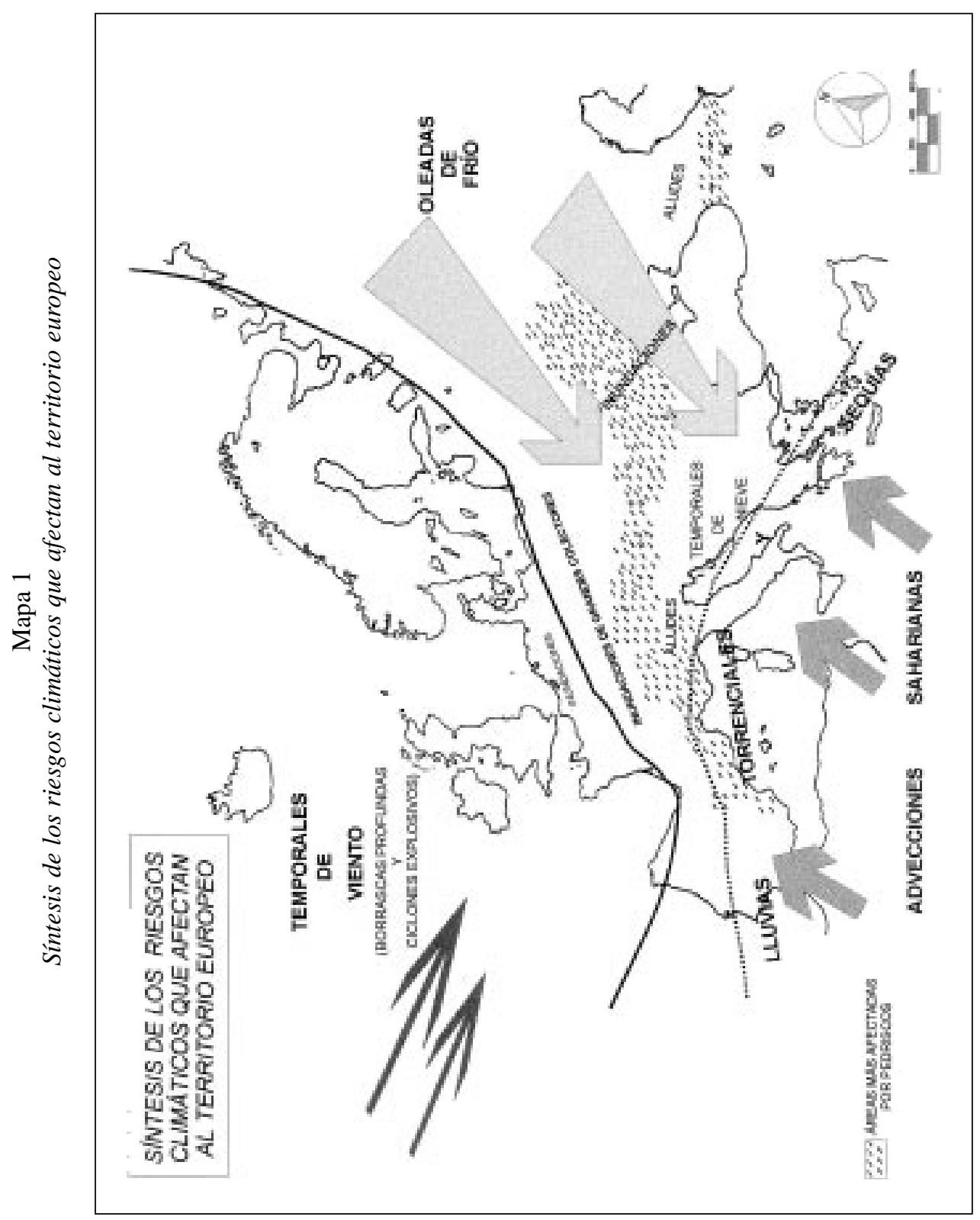


Las inundaciones de los colectores europeos son el riesgo de causa atmosférica más importante en Europa. Conviven dos realidades, los desbordamientos masivos de los grandes colectores (Rhin, Mossa, Danubio, Oder, Vistula, Neisse, ríos rusos) causados por lluvias abundantes y continuadas y/o deshielos rápidos y, por otro lado, avenidas de ríos mediterráneos debidas a lluvias intensas y torrenciales que precipitan abundantes cantidades en escaso intervalo de tiempo (vid. cuadro $n^{\circ} 2$ ). Entre las primeras destacan los desbordamientos del Rhin, Mosa y Sena en diciembre de 1993, inundación de zonas ribereñas de Alemania, Holanda, Bélgica y Francia o, la más importante de enero de 1995, en este mismo sector, que provocó la evacuación de 250.000 personas, 25 muertes y daños evaluados en 3.000 millones de dólares. En julio de 1997 una sucesión de jornadas de tiempo inestable en Europa oriental — vaguada de aire polar marítimo que permaneció en la escena sinóptica, con sucesivas reactivaciones, a lo largo de la primera década del mes-, causó la crecida desmesurada y desbordamiento de los ríos Vístula, Oder y Neisse provocando graves pérdidas económicas y evacuación de miles de personas en el suroeste de Polonia, Chequia y la frontera oriental alemana. En total, cerca de 80 muertos y 192.000 evacuados. La compañía Munich Re evaluó las pérdidas en 5 billones de ecus (vid. figura $\mathrm{n}^{\circ} 1$ ).

En los países mediterráneos europeos los episodios de lluvia intensa otoñal provocan desbordamientos de ríos, rieras y barrancos. En su origen hay que poner en relación la exis-

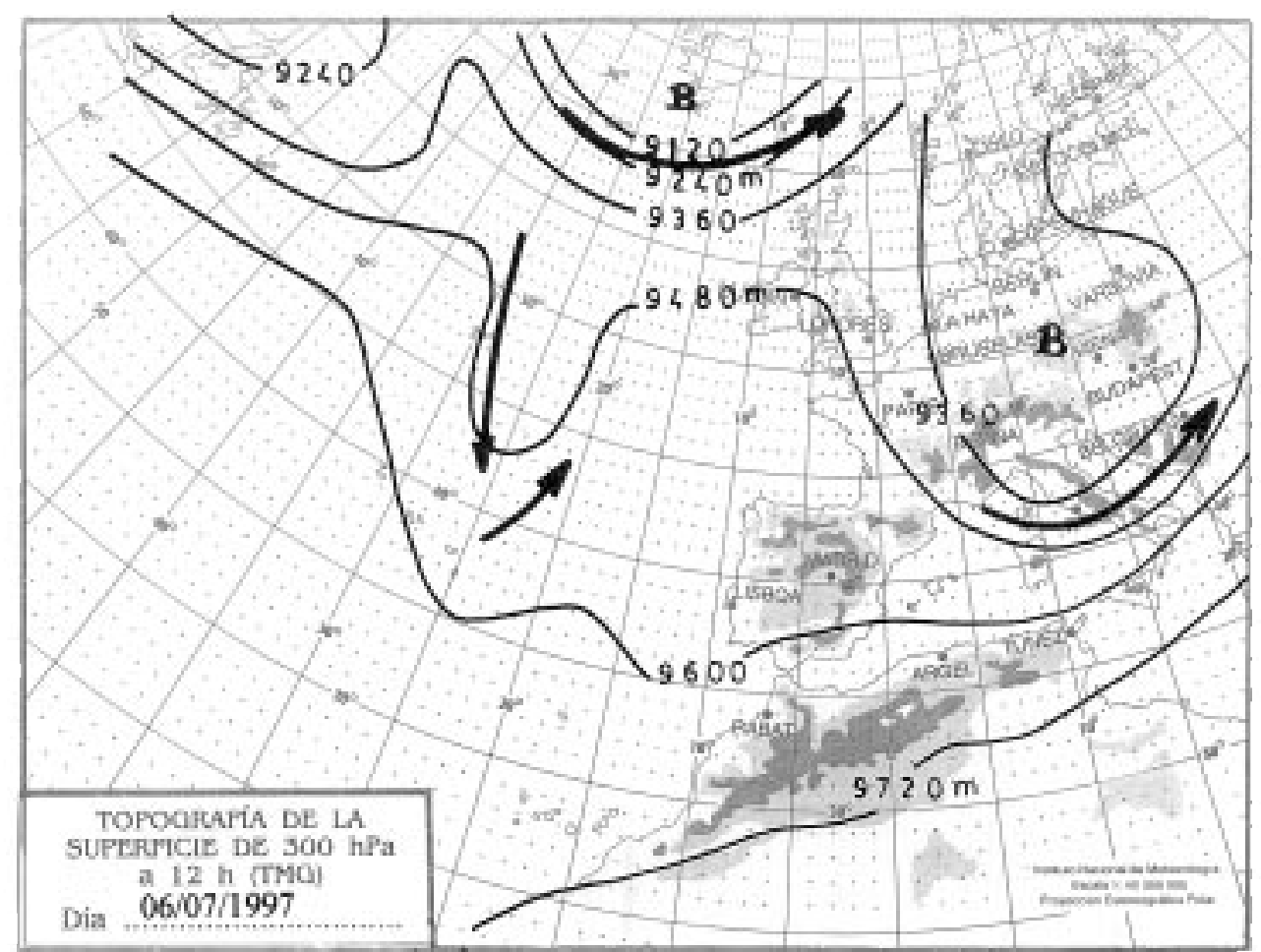

FIGURA 1. Situación atmosférica causante de lluvias abundantes y continuadas sobre Europa central y oriental, origen de la crecida de los ríos Vístula, Oder y Neisse, a principios de julio de 1997. (Fuente: Boletín Meteorológico diario. Instituto Nacional de Meteorología. 6 de julio de 1997. Topografía de $300 \mathrm{hPa}$ ). 
tencia de una orla montañosa terciaria que confiere carácter de cubeta rodeada de montañas al sector occidental del Mediterráneo, la intensa ocupación de llanos litorales, y la presencia, esa época del año, de aguas marinas cálidas, premisa indispensable para la formación de grandes conjuntos convectivos. De manera que las situaciones de inestabilidad atmosférica se saldan con registros de precipitación abundantes y de elevada intensidad horaria y crecida, a veces desaforada, de ríos y barrancos. La localidad de Jávea (España) ostenta el récord europeo de precipitación máxima en 24 h. $(871 \mathrm{~mm}$., el 2 de octubre de 1957). El litoral mediterráneo francés, en particular, el sector comprendido entre la desembocadura del Ródano y la costa azul y, sobre todo, el litoral mediterráneo español son las zonas de mayor riesgo del área mediterránea europea. Destacan las inundaciones de septiembre de 1963 en Cataluña, de octubre de 1982 en Valencia y Alicante, de noviembre de 1987 en el sureste ibérico, septiembre y noviembre de 1989 en diferentes áreas del litoral mediterráneo español, o septiembre de 1992 en el sur de Francia. Esta última se saldó con 63 muertos de las regiones de Vaucluse, Ardiche y La Dôme.

Las prácticas de defensa llevadas a cabo para evitar inundaciones, amen de mejoras en la predicción meteorológica, contemplan medidas estructurales de regulación de caudales (diques y embalses), canalizaciones de tramos conflictivos e instalación de sistemas de alerta automática basados en la implantación de puntos de control que envían información en tiempo real, como los desarrollados, en los últimos años, en Francia (red Cristal), España (SAIH) o el Sistema Eficaz de Aviso de Emergencia (DAEWS) en el Danubio. Sobresale también la serie de obras llevadas a cabo en Holanda para evitar las inundaciones que culminan con la puesta en marcha del Plan Delta, aprobado tras el desastre de febrero de 1953 que causó 1.865 muertos y la inundación de más de 160.000 ha. Esta Plan tenía por objeto la ejecución de una serie de infraestructuras para la prevención de los desbordamientos del Rhin, Escalda y Mosa. Por su parte, la Unión Europea, a través de la DG XII ha puesto en marcha diversos programas de investigación para el estudio del riesgo de inundación en los territorios europeos. Así, en 1996, se inició el programa RIBAMOD para la investigación e intercambio de experiencias de las inundaciones en los países europeos a fin de prevenir las catástrofes de este tipo. Asimismo se ha iniciado el programa AFORISM para la mejora de las comunicaciones entre los distintos estados miembros en caso de inundaciones. Por último, el programa FRAMEWORK tiene por objeto la elaboración de principios rectores para integrar el riesgo de inundación en la planificación urbana y territorial. En este sentido hay que señalar que varios países europeos disponen de legislación (aguas, ordenación del territorio, protección civil) que contempla el tratamiento del riesgo de inundación en los procesos de ordenación espacial.

Las sequías, tienen en Europa, su área de mayor riesgo en los países mediterráneos a favor de la mayor frecuencia que presentan, algunos años, las situaciones atmosféricas de dorsal subtropical que imponen condiciones de estabilidad atmosférica absoluta con penuria de precipitaciones (vid. cuadro $\mathrm{n}^{\circ} 2$ ). Los volúmenes de lluvia de los años secos no alcanzan, en ocasiones, el 50\% de la media. Grecia, sur de Italia y la Península Ibérica, son las áreas europeas más afectadas por este riesgo que causa graves daños en la agricultura y problemas de abastecimiento público de agua. En los últimos lustros destacan las secuencias secas desarrolladas entre 1981-84 y 1992-95. Esta última causó pérdidas económicas en el campo español superiores a 500.000 millones de pts. No faltan, sin embargo, episodios de sequía en las regiones europeas de clima oceánico cuyos efectos no dejan de ser gravosos al afectar áreas poco acostumbradas a la disminución de volúmenes de precipitación. Así, la sequía padecida en algunos países de Europa Occidental entre 1975 y 1976 
Cuadro 2

SITUACIONES ATMOSFÉRICAS CAUSANTES DE EPISODIOS ATMOSFÉRICOS EXTRAORDINARIOS EN EUROPA

\begin{tabular}{|c|c|c|}
\hline Riesgo & Causa atmosférica & Época de máximo riesgo \\
\hline $\begin{array}{l}\text { Inundaciones de grandes } \\
\text { colectores }\end{array}$ & $\begin{array}{l}\text { - Sucesión de borrascas de estructura frontal que atraviesan } \\
\text { Europa vinculadas a circulaciones zonales intensas o } \\
\text { vaguadas de aire polar marítimo }\end{array}$ & $\begin{array}{l}\text { - Meses de invierno (diciembre- } \\
\text { enero) } \\
\text { — Julio-Agosto }\end{array}$ \\
\hline $\begin{array}{l}\text { Lluvias torrenciales en la } \\
\text { cuenca mediterránea }\end{array}$ & $\begin{array}{l}\text { - Vaguadas o depresiones frías situadas sobre la cuenca } \\
\text { Mediterránea }\end{array}$ & - Agosto a noviembre \\
\hline Sequías & $\begin{array}{l}\text { - Presencia frecuente de dorsales de aire tropical sobre } \\
\text { Europa. Si las dorsales se extienden hasta latitudes subpo- } \\
\text { lares, las sequías afectan al norte de Europa (Europa atlán- } \\
\text { tica, paises nórdicos) }\end{array}$ & $\begin{array}{l}\text { - Distinción entre año seco y } \\
\text { secuencia de sequía }\end{array}$ \\
\hline Oleadas de frío & $\begin{array}{l}\text { - Vaguadas de evolución retrógrada (masa de aire polar- } \\
\text { ártica continental) } \\
\text { — Vaguadas de aire ártico marítimo }\end{array}$ & $\begin{array}{l}\text { - Noviembre a marzo } \\
\text { - Heladas tardías (marzo a mayo) }\end{array}$ \\
\hline Aludes de nieve & - Borrascas con precipitaciones de nieve en zonas de montaña & - Diciembre-febrero \\
\hline Advecciones saharianas & - Crestas de aire tropical continental (sahariano) & — Junio-agosto \\
\hline Temporales de viento & $\begin{array}{l}\text { - borrascas atlánticas profundas } \\
\text { - ciclones «explosivos» en la cuenca ártica } \\
\text { - Antiguos ciclones tropicales atlánticos (huracanes) trans- } \\
\text { formados en borrascas enérgicas con estructura frontal }\end{array}$ & $\begin{array}{l}\text { - Todo el año. Mayor intensidad } \\
\text { de vientos en diciembre-abril }\end{array}$ \\
\hline Tormentas de pedrisco & $\begin{array}{l}\text { - Tormentas estivales vinculadas a vaguadas de diversa pro- } \\
\text { fundidad sobre el espacio sinóptico europeo }\end{array}$ & - Junio a septiembre \\
\hline
\end{tabular}

FuENTE: Boletín Meteorológico Europeo. Informes de daños de la DHA (OCHA). Prensa diaria.

causó graves pérdidas en el sector agrícola y obligó a practicar restricciones en el suministro de agua de 17 horas al día en el sur de Inglaterra. Similares efectos tuvo la secuencia de sequía de 1989-91 en el Reino Unido, que se saldó con daños superiores a mil millones libras esterlinas; 1989 fue el más seco de los últimos veinticinco años en Inglaterra; pérdidas elevadas se registraron, asimismo, en las agriculturas de Alemania, Polonia, Checoslovaquia, Hungría y regiones atlánticas de Francia ${ }^{1}$.

Un riesgo climático poco valorado pero de elevada frecuencia en los países europeos de latitudes más septentrionales, durante los meses de noviembre a abril, son los temporales de viento fuerte, ocasionados por borrascas atlánticas profundas o «ciclones explosivos» formados en la cuenca ártica (vid. cuadro $\mathrm{n}^{\circ} 2$ ). La violencia de los vientos que acompañan estas formaciones sinópticas con rachas máximas que superan los $100 \mathrm{~km} / \mathrm{h}$., causan daños en infraestructuras, viviendas y cultivos bajo plástico. Destaca la sucesión de cuatro temporales de viento que sacudió el noroeste de Europa (Gran Bretaña, Irlanda, Alemania, Sue-

1 El año 1989 fue, por contra, uno de los más lluviosos del siglo XX en las regiones del este y sur de la Península Ibérica y en el norte de Marruecos y Argelia. La instalación, con elevada frecuencia, de circulaciones de tipo retrógrado en el espacio sinóptico europeo explica el desarrollo de tempestades tan contrastadas en el norte y sur de Europa y, en definitiva el carácter muy seco y muy lluvioso, respectivamente, del año pluviométrico. 


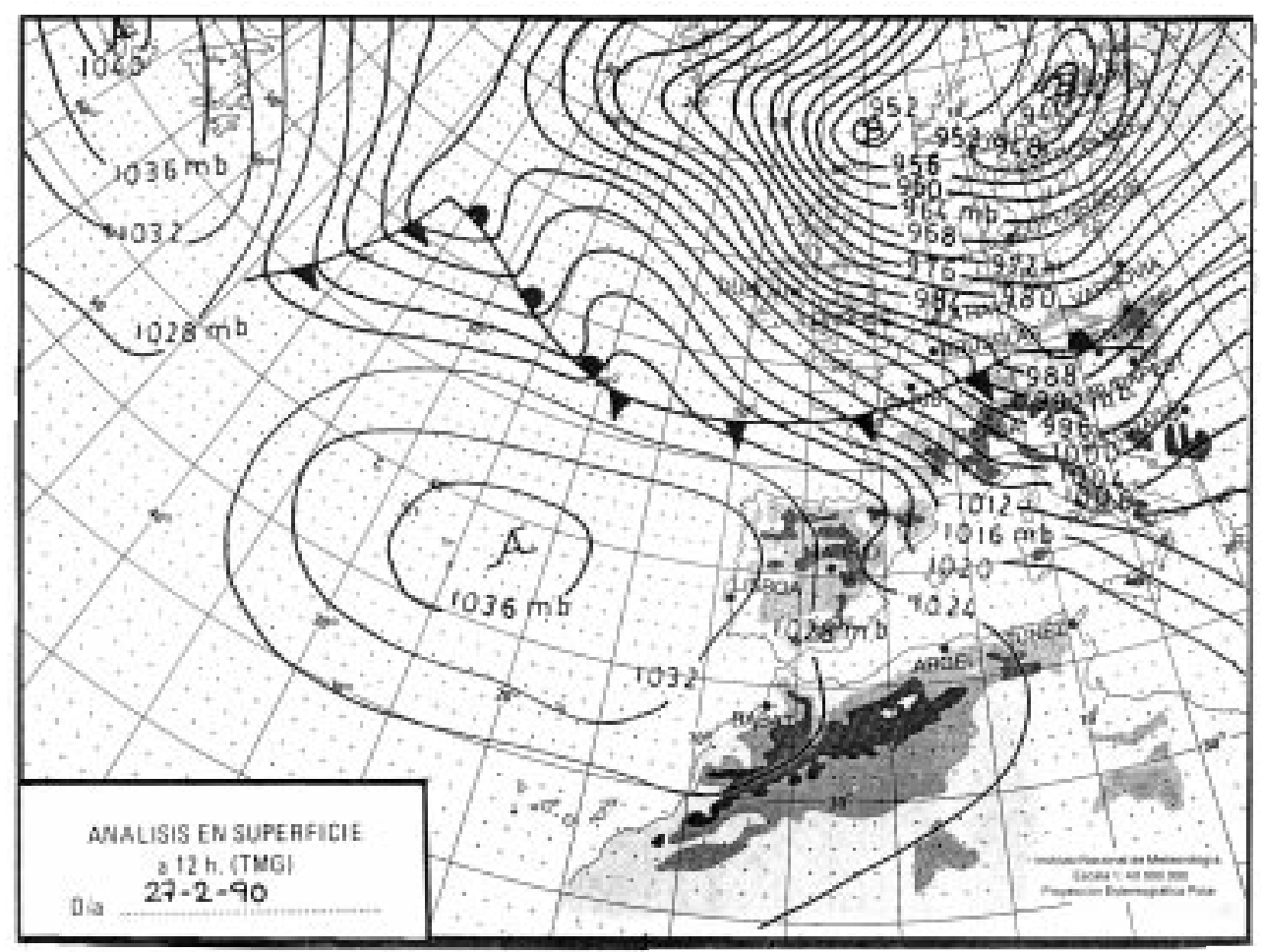

FIGURA 2. Circulación intensa del noroeste sobre Europa occidental y países nórdicos causante de temporal de viento a gran velocidad a finales de febrero de 1990. El mes de febrero de dicho año fue particularmente prolífero en jornadas con circulación de elevado gradiante de presión que ocasionaron ventoleras con graves daños en el área europea señalada. (Fuente: Boletín Meteorológico diario. Instituto Nacional de Meteorología. 27 de febrero de 1990. Análisis en superficie).

cia, Francia, Dinamarca y Holanda) entre finales de enero y principios de marzo de 1990 que elevó las pérdidas económicas por encima de 10.400 millones de dólares (vid. figura $\mathrm{n}^{\circ}$ 2). Otro espacio geográfico con elevada frecuencia de aparición de este evento atmosférico es el litoral suratlántico de Francia y la costa cantábrica española donde sobresalen como episodios significativos de los últimos decenios los daños causados por el llamado huracán «Hortensia» — borrasca atlántica profunda originada a partir de dicho ciclón tropical — en octubre de 1984 o el temporal, más reciente, de febrero de 1996 con pérdidas en las mencionadas regiones de Francia y España evaluadas en 5.000 millones de dólares. En coordinación con la Organización Meteorológica Mundial se ha llevado a cabo el programa FASTEX para el estudio de las borrascas atlánticas y su impacto sobre las regiones de Europa occidental con el objetivo de mejorar la predicción a medio plazo de los temporales de viento.

Para la prevención de los efectos causados por el viento a gran velocidad en infraestructuras, medios costeros y cultivos se han construido diques y escolleras de defensa en el litoral e instalado cortavientos — naturales y artificiales - para proteger frutales e invernaderos. Ejemplos prototípicos de estos últimos se localizan en los deltas del Ródano y Ebro en la Europa Mediterránea y en los Países Bajos en la fachada atlántica. 


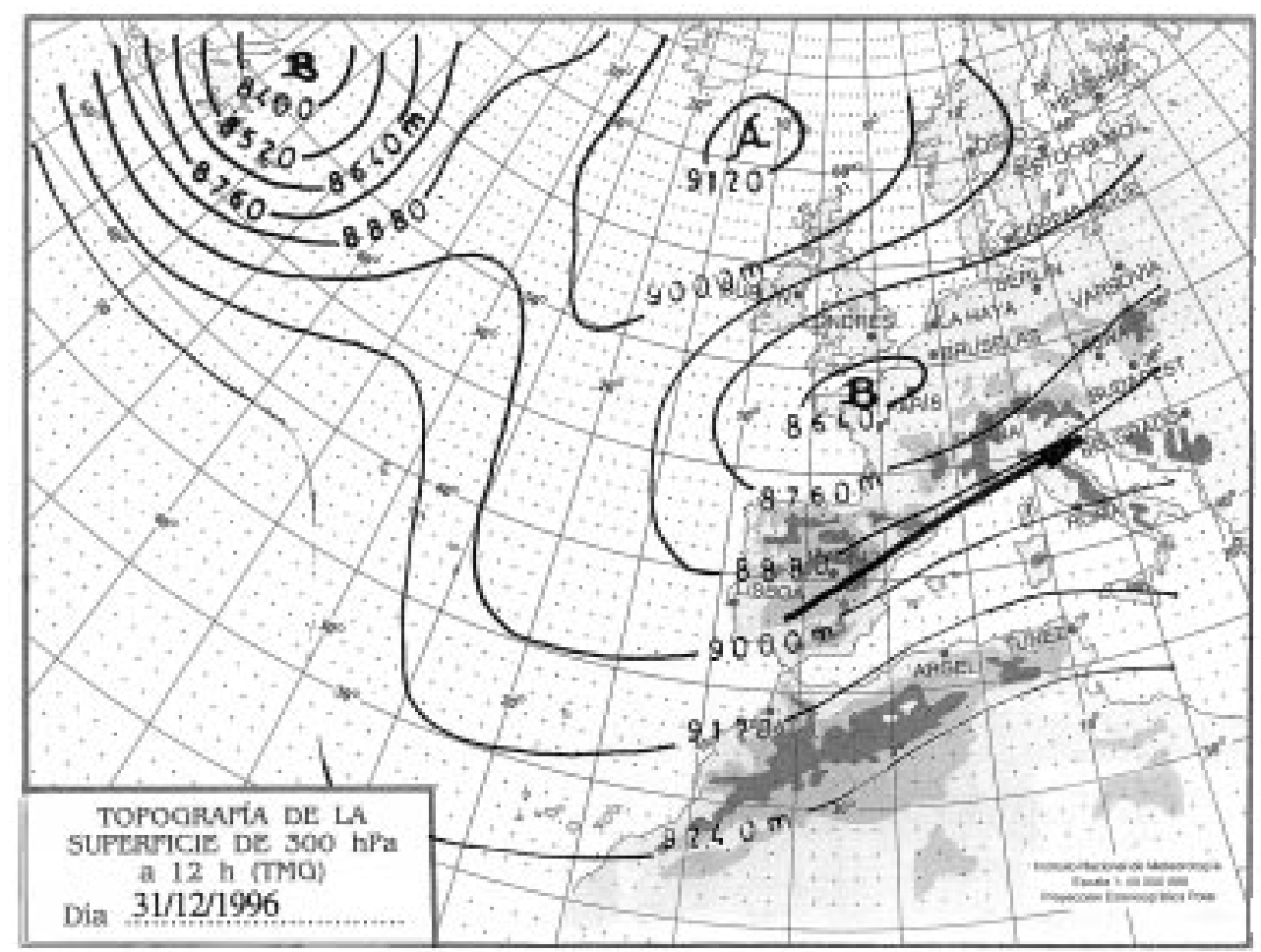

FIGURA 3. Vaguada de evolución retrógrada sobre el espacio sinóptico europeo causante de la «invasión siberiana» que causó cerca de 400 muertos en diversos países de Europa oriental durante las navidades de 1996/7. (Fuente: Boletín Meteorológico diario. Instituto Nacional de Meteorología. 31 de diciembre de 1996. Topografía de $300 \mathrm{hPa}$ ).

Las oleadas de frío provocan, anualmente, elevadas pérdidas humanas en Rusia y países de Europa oriental (Polonia, Repúblicas Bálticas, Bielorrusia, Ucrania, Eslovaquia, Hungría). La llegada de masas de aire ártico marítimo y siberianas hacen caer los registros de temperatura mínima por debajo de $-15^{\circ} \mathrm{C}$, e incluso menores (vid. cuadro $\mathrm{n}^{\circ} 2$ ). Graves daños económicos para la actividad agraria causan las expansiones de estas masas de aire que alcanzan los países mediterráneos (Grecia, Croacia, Servia-Montenegro, Bosnia-Herzegovina, Albania, Macedonia, Italia, litoral mediterráneo de Francia y España) vehiculadas por vaguadas profundas de evolución retrógrada. En estos casos, regiones poco acostumbradas a bajas temperaturas invernales ven perderse las cosechas de frutales y productos hortícolas que se encuentran en producción en esas fechas. Destacan, al respecto, los episodios de frío intenso de los últimos decenios en Europa destacan las invasiones frías de mediados de febrero de 1956 y de las navidades de 1970-71, de la primera quincena de enero de 1985 o de las navidades de 1996-97 en Europa occidental y mediterránea. La ola de frío de enero de 1985 ocasionó cuantiosos daños en los cultivos de la República Federal Alemana, Suiza, Austria, Francia y España. La causa de su génesis fue la instalación de una profunda vaguada de aire ártico-polar continental sobre toda Europa. La lengua de aire frío provocó registros térmicos inferiores a $-20^{\circ} \mathrm{C}$ en el norte 
y centro de Europa, y de $-15^{\circ} \mathrm{C}$ en algunas localidades de los países mediterráneos. Se registraron copiosas nevadas, entre las mayores de que hay noticia, en Magadiano (Suiza) cayeron, entre dos días, 14 y 16 de enero, 97 centímetros. Efectos catastróficos tuvo la «invasión siberiana», causada por la instalación de una vaguada de evolución retrógrada sobre Europa (vid. figura $\mathrm{n}^{\circ} 3$ ), ocurrida en las navidades de 1996-97, con registros térmicos mínimos de $-30^{\circ} \mathrm{C}$ y menos en Moscú y otras capitales del este de Europa, con cerca de cuatrocientos muertos.

Relacionado con precipitaciones de nieve en zonas de montaña se encuentra el riesgo de avalanchas de nieve o aludes. Los aludes se producen con precipitaciones de nieve abundantes repetidas en breve intervalo. No obstante, el riesgo de aludes, además de la abundancia de nieve, depende, en gran medida, de las condiciones topográficas del área afectada; $y$, junto a ello, una vez que la masa de nieve está presta para desprenderse, temperatura ambiente y viento son los factores desencadenantes del derrumbamiento de aquélla. La región alpina es el área más afectada por estos eventos destacados sobresaliendo la avalancha de 1919 en el Tirol austríaco que causó la muerte de 10.000 personas y la de Blons, en 1954, también en Austria, con 380 muertos. El último episodio de consecuencias dramáticas tuvo lugar en el valle de Chamonix, en los Alpes franceses, el 9 de febrero de 1999, cuando una avalancha de nieve de seis metros de altura y $200 \mathrm{~m}$. de ancho sepultó varias viviendas en la localidad de Tour, al pie del Mont Blanc, causando 13 muertos.

Para la prevención de avalanchas Francia ha puesto en marcha, desde 1985, una campaña anual de predicción de posibles avalanchas en el sector alpino, Pirineos y Córcega. Para ello se ha elaborado una cartografía de áreas de riesgo que establece una gradación del peligro (zona roja, azul y blanca) y asimismo, en las áreas de montaña, se difunden boletines diarios de avalanchas, en los que se indica el grado de riesgo de aludes según el modelo predictivo «Crocus». También en área alpina (Suiza, Italia, Austria y Francia), el gran auge que ha experimentado la práctica de deportes de invierno han motivado la realización de obras de defensa pasiva ante avalanchas, consistentes en abrigos subterráneos y mallas de contención de las masas de nieve en la cima de las montañas.

En sentido totalmente contrario, los países del sur de Europa se ven azotados en verano por expansiones de la masa de aire sahariana, que, en los meses de junio a agosto, provocan incrementos súbitos de temperaturas, descenso de la humedad relativa y sequedad ambiental que se suelen acompañar de incendios forestales, generalmente intencionados, y afecciones cardio-respiratorias que pueden llegar a ser funestas para los habitantes de las regiones afectadas (vid. cuadro $\mathrm{n}^{\mathbf{0}} 2$ ). En ocasiones, la intensidad de las expansiones alcanza países tan alejados de la fuente norteafricana como Gran Bretaña o los países nórdicos. Destacan, en este ámbito, los olas de calor muy intensas de junio de 1983 (44 muertos en Grecia y 40 en el sur de Italia) y de julio de 1994 en la Península Ibérica $\left(46,1^{\circ} \mathrm{C}\right.$ en Murcia), que causó 41 muertos.

Por último, hay que mencionar los daños en los cultivos provocados por las tormentas de granizo que descargan entre los meses de junio y septiembre en algunas regiones de Europa (vid. cuadro $\mathrm{n}^{\circ}$ 2). Las áreas de mayor frecuencia de aparición de estos episodios son las regiones caucásicas de la antigua URSS (en particular la república de Georgia), Ucrania y centro de Rusia, en torno a Moscú, suroeste de Polonia — Wroclaw—, Chequia, el norte de Italia (llanura del Pó), sur de Francia, Suiza, Austria, lander del sur de Alemania y litoral mediterráneo y valle del Ebro en España. En estas áreas se han llevado a cabo a lo largo del presente siglo, y aún se practican, actuaciones de defensa frente a los granizos (cohetes, siembra con yoduro de plata y mallas de plástico sobre los cultivos). 


\section{Bibliografía}

AGENCIA EUROPEA DE MEDIO AMBIENTE (1998) Medio Ambiente en Europa. El informe Dobøø Edición española a cargo del Ministerio de Medio Ambiente y la Oficina de Publicaciones Oficiales de las Comunidades Europeas, Madrid, 712 pp.

Anuario Natural disasters in the world. Instituto Tecnológico Geominero de España. Años 1990 a 1995.

Boletín de la OMM (varios años).

FRAMPTON, S., CHAFFEY, J., Mc NAUGHT, A. and HARDWICK, J. (1996) Natural hazards. Causes, consequences and management. Hodder \& Stoughto, London, 126 pp.

GIL OLCINA, A. y OLCINA CANTOS, J. (1997) Climatología General. Ed. Ariel, Barcelona, $579 \mathrm{pp}$.

Informes de catástrofes de la OCHA (United Nations Office for the Coordination of Humanitarian Affairs). Años 1996 a 1999.

OLCINA CANTOS, J. (1994) Riesgos climáticos en la península ibérica. Acción Divulgativa, Madrid, $440 \mathrm{pp}$.

UNITED NATIONS (1997) Floods. People at risk, strategies for prevention. Department of Humanitarian Affairs. New York and Geneva, 93 pp. 